\title{
A Case of Autoimmune Hepatitis with extremely high level
}

of alpha fetoprotein

Hripsime Apresyan ${ }^{1,2}$, Sose Margaryan², Tatev Grigoryan¹, Arevhat Karapetyan¹; Vigen Asoyan ${ }^{1,2}$

1Yerevan State Medical University, Department of Infectious diseases, Yerevan/AM

2“Nork" Infectious Clinical Hospital, Yerevan/AM

\section{Background}

Autoimmune hepatitis (AlH) is a form of chronic hepatitis of unknown etiology. Two types of childhood $\mathrm{AlH}$ are recognized according to seropositivity: smooth muscle antibody (SMA) and/or antinuclear antibody (ANA), which is AlH type 1; and antibodies to liverkidney microsome type 1 (anti-LKM1), which is AlH type 2. Our goal is to introduce rare case of patient with autoimmune hepatitis which developed after enteroviral infection and had extremely high level of alpha fetoprotein (AFP).

\section{Methods \& Materials:}

We used the medical chart of patient with autoimmune hepatitis admitted to "Nork" Infectious clinical hospital

\section{Results:}

The 5 years old boy admitted to hospital with fever, abdominal pain, weakness, jaundice, disorders of consciousness. A week before he had fever, diarrhea, vomiting. Laboratory data: CBC- RBC, WBC, PLT-normal,. Liver enzymes, bilirubin and IgG levels were elevated as well, as aFP and ANA.

\begin{tabular}{|l|l|l|}
\hline Test & Result & $\mathbf{N}$ \\
\hline $\mathrm{Hb}$ & 102 & $120-140 \mathrm{~g} / \mathrm{l}$ \\
\hline ESR & 64 & $4-10 \mathrm{~mm} / \mathrm{h}$ \\
\hline ALT & 2440 & $0-42 \mathrm{U} / \mathrm{L}$ \\
\hline AST & 1640 & $0-37 \mathrm{U} / \mathrm{L}$ \\
\hline aFP & 7685 & $>7.02 \mathrm{ng} / \mathrm{ml}$ \\
\hline total bilirubin & 272.6 & $8.55-20.5 \mathrm{mmol} / \mathrm{l}$ \\
\hline direct bilirubin & 180.4 & $0-5.1 \mathrm{mmol} / \mathrm{l}$ \\
\hline IgG & 22,96 & $7,0-16,0 \mathrm{~g} / \mathrm{l}$ \\
\hline ANA & $1: 320$ & $1:<10$ \\
\hline INR & 3,29 & $0.82-1.18$ \\
\hline
\end{tabular}

INR 3,29 (N 0.82-1.18), CEA-negative, Anti-dsDNA, LDH-normal, Copper total 828ug/l (N9001900), LKM $1:<10 \quad(\mathrm{~N} 1:<10), \quad$ SMA $1:<10$ $(\mathrm{N} 1:<10)$. Stool test for Enterovirus - positive.
Serology and/or PCR for HCV, HBV, HAV, HEV, EBV, CMV, Parvovirus B19, Brucellosis, Yersinosis, Pseudotuberculosis, Leishmaniasis, Leptospirosis negative.

Liver biopsy showed autoimmune hepatitis (METAVIR Grade 2, stage 1).

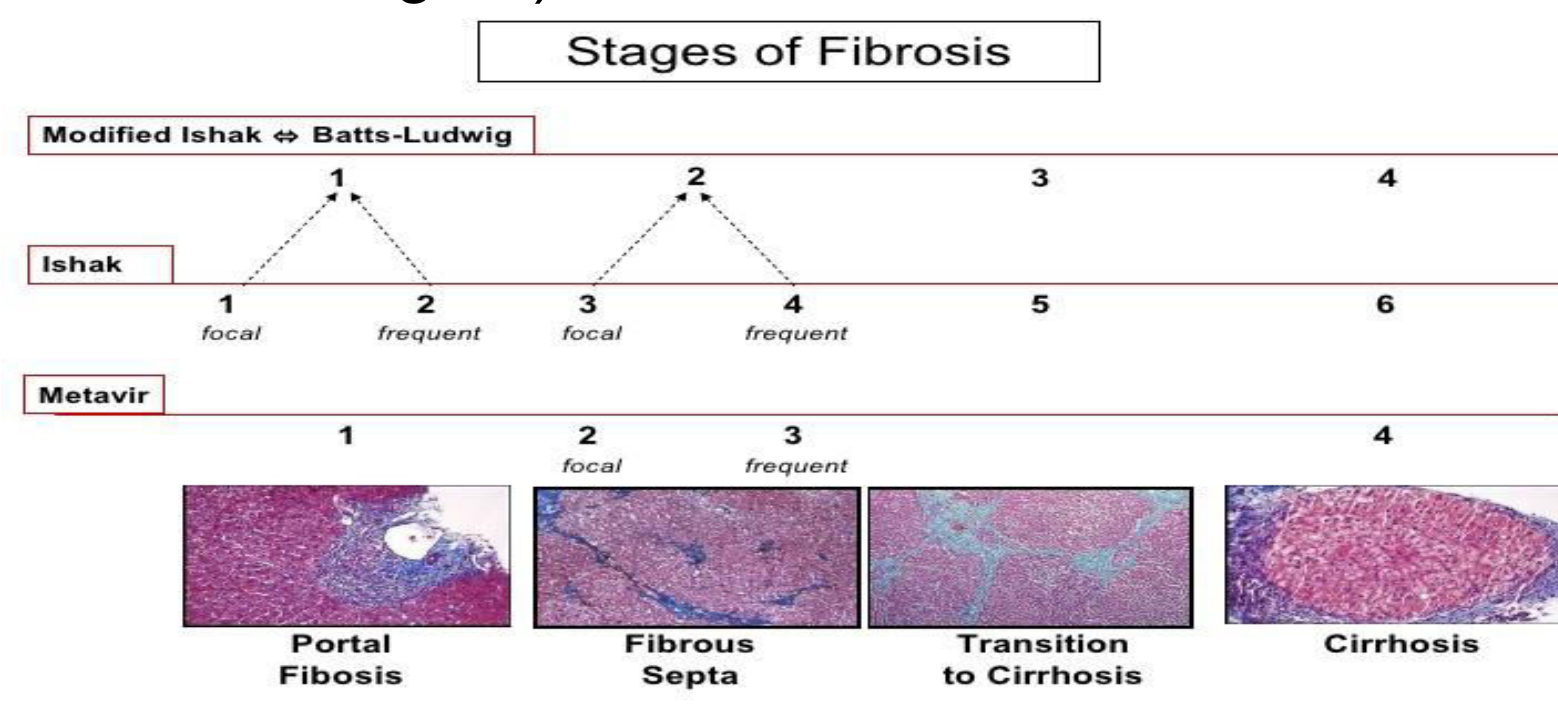

\section{Treatment:}

Immediate therapy with high-dose prednisolone therapy was started, then we decreased prednisolone dose and added azathioprine. As a result, we had improvement of patients' condition, clinical findings and laboratory values.

\section{Conclusion:}

Autoimmune hepatitis followed by enteroviral infection. Extremely high level of alpha fetoprotein is not always marker of tumor. 